\section{TRAIL, DR5 and caspase 3-dependent apoptosis in vessels of diseased human temporomandibular joint disc. An immunohistochemical study}

\author{
C. Loreto, ${ }^{1}$ L.E. Almeida, ${ }^{2}$ M.R. Migliore, ${ }^{3}$ \\ M. Caltabiano, ${ }^{3}$ R. Leonardi ${ }^{3}$
}

'Department of Anatomy, Diagnostic Pathology, Forensic Medicine, Hygiene and Public Health, University of Catania, Catania, Italy; ${ }^{2}$ Center for Health and Biological Sciences, Pontifical Catholic University of Paraná, Curitiba, Brazil; ${ }^{3}$ Department of Medical and Surgical Sciences, $2^{\text {nd }}$ Dental Unit, University of Catania, Catania, Italy

\section{Abstract}

To evaluate the apoptosis involvement in the angiogenesis as a self-limiting process in patients with temporomandibular joint (TMJ) degenerated disc vessels, we assessed, by immunohistochemistry, the detection of TRAIL, its death receptor DR5 and caspase 3. TRAIL, its death receptor DR5 and caspase 3 expression were studied by immunohistochemistry in 15 TMJ discs displaced without reduction and in 4 unaffected discs. These apoptosis molecules were detected in the intima and media layers of newly formed vessels affected discs. In conclusion, vessels apoptosis activation in TMJ disc with ID could be regarded as a self-limiting process that try to leads to vessel regression; in this way an inhibition of angiogenic vessels may prove a key strategy in limiting pathological angiogenesis, by cutting off blood supply to tumors, or by reducing harmful inflammation.

\section{Introduction}

The formation of new blood vessels is an essential part of many physiological and pathological processes including embryogenesis, wound healing, formation of blood supply to tumors or ischemic tissue and as a driver of inflammatory diseases. ${ }^{1-3}$

Adult human temporomandibular joint (TMJ) disc is devoid of blood vessels, except for the bilaminar zone. ${ }^{4,5}$ The absence of a vascular supply and the compact arrangement of the fibrous component are considered to be the morphological characteristics that allow the human TMJ disc to bear the compression forces of articulation. ${ }^{6}$ In contrast, a high den- sity of blood vessels is described in discs affected by internal derangement (ID) of the

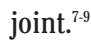

ID involves an altered anatomical relationship of the disc-condyle complex and it is likely to lead to histopathological changes that culminate in tissue degeneration as occurs in disc displacement TMJ discs. ${ }^{10-17}$ Very little literature data concerning the distribution of the newly differentiated capillaries in TMJ ID discs exists. Since blood capillaries increase in number with the degree of inflammation during tissue repair, previous authors have evaluated CD34 immunoreactivity not only in the walls of blood capillaries within internal derangement TMJ disc, but also in the posterior loose connective tissue of bilaminar zone. CD34 is a human cell antigen usually expressed by hematopoietic bone marrow progenitor cells and it is used as a sensitive marker of vascular endothelium. The previous findings showed that CD34 immunostaining appear to be correlated with the severity of TMJ ID. ${ }^{18}$ It has also been demonstrated that in inflammatory, degenerative and hypoxial states and/or mechanical stress, several cytokines as interleukin $1 \beta$ (IL-1 $\beta$ ), prostaglandin E (PGE), epidermal growth factor $\beta 1$ (EGFR- $\beta 1$ ), and tumor necrosis factor $\alpha$ (TNF$\alpha)$ could activate the vascular endothelium and initiate angiogenesis inducing the expression of a cytokine called vascular endothelial growth factor (VEGF). ${ }^{19-22}$ Some authors demonstrated that VEGF was also expressed by chondrocyte-like cells of perforated TMJ discs, showing a similar distribution with chondromodulin-1 (ChM1) glycoprotein, postulating that the existence of ChM-1 could neutralize the angiogenic effect of VEGF preventing, in this way, blood vessel invasion at the arthropatic site.

In hypertrophic cartilage VEGF seems to be released by chondrocytes in a paracrine way, using endothelial cells as a target ${ }^{23}$ and that it is essential to correct directional growth and cartilage invasion by blood vessels. Moreover, it has been argued that during an inflammatory process, VEGF could contribute, by chemotaxis of macrophage and promoting angiogenesis, to the activation of cellular pathways that induce apoptosis in such proliferative regions.

Apoptosis, or programmed cell death, is an integral part of development as seen in embryogenesis, normal tissue turnover, cellular homeostasis and a variety of diseases resulting from its dysregulation. ${ }^{24}$

Apoptosis processes involve a Fas or tumor necrosis factor (TNF)- $\alpha$ associated extrinsic pathway and a mitochondrial associated intrinsic pathway. In particular, tumor necrosis factor-related apoptosis-inducing ligand (TRAIL) Apo-2L is a type II membrane protein, which can be proteolytically cleaved by cysteine pro-
Correspondence: Carla Loreto, Senior Lecturer in Human Anatomy, Department of Anatomy, Diagnostic Pathology, Forensic Medicine, Hygiene and Public Health, University of Catania, via $S$. Sofia 87,95131 , Catania, Italy.

Tel. +39.095.3782043 - Fax: +39.095.3782046 E-mail: carla.loreto@unict.it

Key words: temporomandibular joint disc, vessels, apoptosis.

Received for publication: 21 June 2010. Accepted for publication: 5 August 2010.

This work is licensed under a Creative Commons Attribution 3.0 License (by-nc 3.0).

CC Copyright C. Loreto et al., 2010

Licensee PAGEPress, Italy

European Journal of Histochemistry 2010; 54:e40 doi:10.4081/ejh.2010.e40

teases to a soluble form, ${ }^{25}$ as also shown for TNF- $\alpha$ and CD95 (Apo-1/Fas) ligand. When TRAIL binds a death receptor, the death inducing signalling complex assembles at the death receptor domain, resulting in caspase 8 activation that causes direct cleavage of caspase 3 into active subunits that execute apoptosis. ${ }^{26}$ Notably, the vessel wall is a rich source of cysteine proteases, ${ }^{27}$ which suggests that TRAIL/TRAIL-R systems probably play a physiological role in vascular biology.

Hence in this paper, we examined, through immunohistochemistry, the detection of TRAIL, its death receptor DR5 and caspase 3 in TMJ degenerated disc vessels in order to evaluate the apoptosis involvement in angiogenesis as a self-limiting process.

\section{Materials and Methods}

\section{Patients and tissues}

Specimens were 15 displaced TMJ discs from the archives of the Pontifical Catholic University of Paraná, Curitiba, Brazil. The study was approved by the local ethics committee. The informed consent of each patient was obtained before disc removal. Discs came from 12 women and 3 men with TMJ ID. All had anterior disc displacement without reduction (ADDwoR), as confirmed by clinical history, physical examination and magnetic resonance imaging (MRI). Their mean age at the time of surgery was 37.2 years $( \pm 4.4)$; the mean interval from ID symptom onset to surgery was 7.9 months $( \pm 0.6)$. Unassisted maximum mouth opening (MM0), determined with a millimeter ruler as interincisal distance, and a visual analog scale (VAS), to measure pain intensity in the preceding week, were used to assess disease severity. The VAS anchor points were 0 
for "no pain" and 100 for "the worst imaginable pain." These data are reported in Table 1.

The diagnosis that led to surgery was TMJ ID with pain and functional impairment. Inclusion criteria were: i) unsuccessful nonsurgical treatment; ii) TMJ tenderness to palpation; and iii) TMJ pain or interference with mandibular movements. Exclusion criteria were: i) other TMJ diseases; ii) dentofacial deformity; ii) major jaw trauma; iv) previous TMJ surgery; and v) previous TMJ steroid injections. After removal, all discs were seen to be macroscopically deformed, none having a normal biconcave shape.

Discectomy has come under increasing attack as the standard therapy for disc displacement, with a number of surgeons now favoring a conservative approach and other researchers still believing in its value. ${ }^{28-30}$ Disc removal is therefore ethically justified. This small sample of whole TMJ discs was investigated because they provide exhaustive information on the characteristics of tissue degeneration.

Four virtually unaffected human TMJ discs from the collection of the Anatomy Institute of Catania University, Catania, Italy, were studied for comparison. These paraffin-embedded autopsy specimens from one male and three female subjects (mean age $49.7 \pm 4.4$ years) were selected because the donors' clinical histories were negative for generalized joint disease or TMJ arthropathy. On dissection the discs showed no macroscopic signs of degenerative or inflammatory joint disease or displacement. They were stained with Harry's hematoxylin and exhibited no detectable pathological changes on light microscopy.

\section{Immunohistochemistry}

For the immunohistochemical staining the discs were fixed overnight in $10 \%$ neutral buffered formalin (Bio-Optica, Milan, Italy). After fixation and overnight washing, each disc was sectioned through its center along a parasagittal plane, perpendicular to its long axis. Each tissue block was dehydrated in graded ethanol, and embedded in paraffin preserving the longitudinal anatomical orientation. Specimens were sectioned at a thickness of 5 $\mu \mathrm{m}$ and placed on silanized glass slides (the anterior band being always on the right side of the slides). Endogenous peroxidase activity was quenched by treatment with $3 \% \mathrm{H}_{2} \mathrm{O}_{2}$ for $10 \mathrm{~min}$. Non-specific binding of antibodies was blocked by normal horse/goat serum treatment [diluted 1:20 in phosphate buffered saline (PBS), $0.1 \%$ bovine serum albumin (BSA)]. The sections were irradiated $(5 \min \times 3)$ in capped polypropylene slide-holders with citrate buffer ( $\mathrm{pH} 6)$, using a microwave oven $(750 \mathrm{~W})$ to unmask antigenic sites.

A rabbit polyclonal anti-caspase 3 antibody

Table 1. Clinical characteristics of patients with anterior disc displacement without reduction.

\begin{tabular}{ccccccc} 
& \multicolumn{2}{c}{$\begin{array}{c}\text { Patients' age } \\
\text { mouth opening }\end{array}$} & \multicolumn{2}{c}{ Unassisted } & \multicolumn{2}{c}{ Visual analog scale } \\
maximum
\end{tabular}

MV, mean value; SD, standard deviation.

(Cell Signaling Technology, Inc., Denver, MA, USA), a rabbit polyclonal anti-TRAIL (Santa Cruz Biotecnology, Inc., CA, USA) and a rabbit polyclonal anti-DR5 (Novus Biologicals, Inc., Littleton, USA) used respectively at 1:100, 1:20 and 1:20 working dilution (in PBS, $0.1 \%$ BSA), were applied on each section and incubated overnight at $+4^{\circ} \mathrm{C}$ in a moist chamber. Immunocomplexes were detected by incubation with the secondary antibody and then with streptavidin-peroxidase complexes for 15 mins each at room temperature (LSAB2/HRP kit, DAKO, Denmark). After rinsing in 3 changes of PBS, the immunoreaction was visualized by incubating sections in a $0.1 \% 3.3$ '-diaminobenzidine and $0.02 \%$ hydrogen peroxide solution (DAB substrate kit, Vector Lab., Burlingame, CA, USA) for $4 \mathrm{~min}$. The sections were lightly counterstained with Mayer's haematoxylin (Histolab Products AB, Goteborg, Sweden) and finally mounted on GVA mount (Zymed Laboratories Inc., San Francisco, CA, USA).

\section{Evaluation of immunohistochemistry}

TRAIL, DR5 and caspase 3 stain intensity and the proportion of immunopositive cells were examined, blinded by light microscopy and recorded. Intensity of staining (IS) was graded on a scale range from 0 to 4 , according to the following semiquantitative assessment: $0=$ no detectable staining, $1=$ weak staining, $2=$ moderate staining, $3=$ strong staining, $4=$ very strong staining. The percentage of TRAIL, DR5 and caspase 3 immunopositive cells (extent score=ES) was also independently evaluated and scored as a percentage of the final number of 200 cells in four categories: $0 \leq 5 \% ; \quad 1=6-30 \% ; \quad 2=31-50 \% ; 3 \geq 50 \%$, and $4 \geq 75 \%$. Counting was performed at X 200 magnification. The final staining score (FSS) was derived from the sum of the intensity score added to the extent score.

\section{Positive and negative control}

This was performed to test the specific reaction of the primary antibody at protein level.

For positive control testing basal cell carcinoma tissue was exposed to an immunoperoxidase process. For negative controls, randomly selected TMJ disc sections were treated with normal rabbit serum instead of the specific antibody.

\section{Statistical analysis}

Data were analyzed using the MannWhitney U-tests; $\mathrm{P}<0.05$ were considered significant. Mean and standard deviation were calculated for both the FSS and HDS. All data were analyzed with the SPSS program (SPSS ${ }^{\circledR}$ release 16.0, Chicago, IL, USA).

\section{Results}

All TMJ patients had been unsuccessfully treated with other various interventions for at least 8 months prior to surgery. The control discs showed preservation of multidirectional collagen bundles, predominately fibrocyte-like cell populations with few chondrocytes-like cells aggregates, and absence of clefts or fraying and vascular vessels. In contrast diseased disc sections, stained with hematoxylin showed a different degree of morphologic damage, ranging from an altered collagen bundle structure to fragmention and the presence of newly formed vessels. A high immunoexpression of TRAIL (Figure 1 A, B), its receptor DR5 (Figure $2 \mathrm{~A}, \mathrm{~B}$ ) and caspase 3 (Figure $3 \mathrm{~A}, \mathrm{~B}$ ) was demonstrated in the intima and media layers of newly formed vessels where cells were strongly positive (IS score=3). The mean FSS of all samples was $4.60 \pm 0.54$ (range 3.4-5.8).

Immunohistochemical reactivity for TRAIL and caspase- 3 was detected in cells cytoplasm, and the immunoexpression of DR5 was recognized in cell membrane and cytoplasm.

\section{Discussion}

TMJ ID is often accompanied by chronic inflammatory changes including growth of small new vessels. ${ }^{31-34}$ It would seem that these degenerative changes, as in other joints, are influenced by the kind (anterior disc displacement with or without reduction) and the degree of disc displacement. Our study evidenced a high immunoexpression of TRAIL, its receptor DR5 and caspase 3 in the intima and media layers of newly formed vessels that reflects an activation of the apoptosis mechanism in these structures. Apoptosis process is 
in fact activated by the extrinsic pathway, through TRAIL which cross-linking DR4 and DR5 receptors death on the surface of target cells particularly in microvascular endothelium as mechanism of defence.

Some authors have just tried to understand how the process of formation of new vessels, including endothelial proliferation, migration and tube formation, is limited through induction of endothelial apoptosis, which leads to vessel regression. However, literature reports on the pro-angiogenetic or anti-angiogenetic action of TRAIL, in in vitro studies, showed contrasting results. Some authors evidenced the stimulatory effect of TRAIL on cell endothelial proliferation and its inducing activation of Akt and Erk that leads to endothelial proliferation, increased cell migration and tube formation without altering endogenous endothelial expression of VEGF ${ }^{35,36}$ while others, on the contrary, demonstrated that TRAIL was found to inhibit tube formation, cell numbers and endogenous VEGF expression. ${ }^{37}$ Probably the anti-angiogenic action of TRAIL is induced by higher doses of this ligand. ${ }^{38}$ Actually, the growth of microvessels by VEGF acts through Akt pathway and can be blocked when Akt is inhibited by various anti-angiogenic factors namely angiotensin II and thromboxane A2. ${ }^{39,40}$ The ability of TRAIL to activate the antiapoptotic PI3k/Akt pathway in endothelial cells is also an unexpected finding. ${ }^{41}$ A possible explanation is that the PI3k/Akt impairs the activation of the apical caspases by inhibiting the recruitment of procaspase- 8 to the deathinducing signalling complex. ${ }^{42}$ Really, as for others morphological features just observed in TMJ diseases, only restricted and focal areas of new vascular profiles have been revealed.

Thus, our present study sustains the hypothesis that angiogenesis reports in degenerative disc tissue are maintained localized thanks to the apoptotic process. In particular, we demonstrated both an activation of the process through the receptor pathway and the progression of cell death through the activation of the executioner caspase 3 that, in turn, leads to cytoskeletal proteins degradation and DNA fragmentation. It is suggested that TRAIL selectively binds death receptor DR5 endothelial cells in a dose dependent manner and enhance apoptosis by caspase 8 and caspase 3 pathway. Our previous study on TMJ disc ID demonstrated that TRAIL was overexpressed in apoptotic chondrocyte like cells, ${ }^{43,44}$ tissue apoptotic cell death seems to be responsible for disc tissue degeneration being correlated with the severity of disc pathologic findings. ${ }^{45-47}$ For patients with complete TMJ meniscus dislocation with internal derangement, some indications that this tissue is undergoing adaptive changes include the presence of thickened arterial walls suggesting a decreased blood flow. ${ }^{48}$
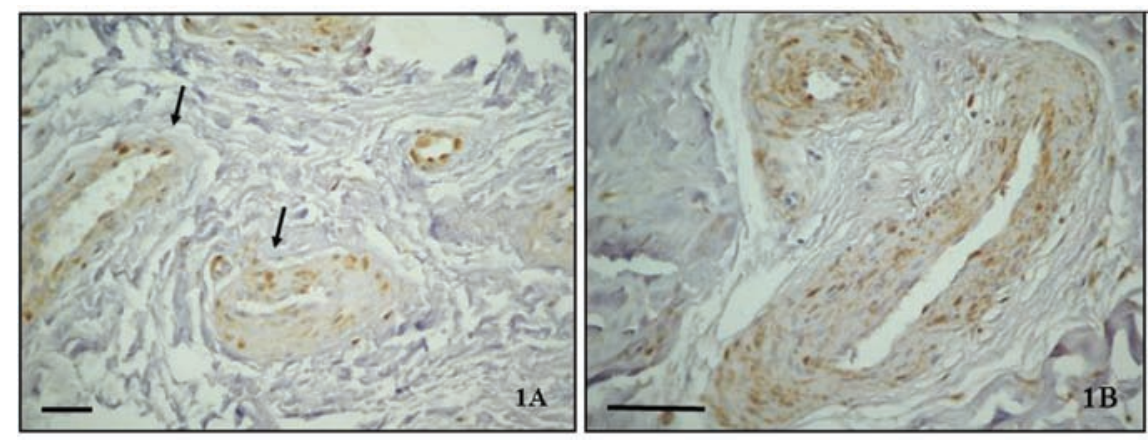

Figure 1. (A) TRAIL immunostaining in the posterior band of TMJ ID disc (x40); (B) Immunopositive vascular vessels are indicated with arrows (x80). Bar: $100 \mu \mathrm{m}$.
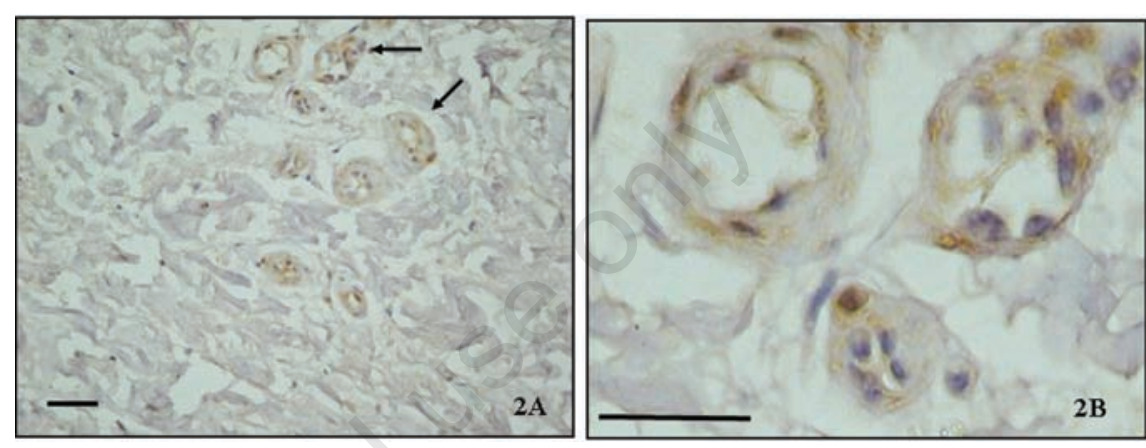

Figure 2. (A) DR5 immunostaining in the posterior band of TMJ ID disc (x40); (B) Immunopositive vascular vessels are indicated with arrows (x100). Bar: $100 \mu \mathrm{m}$.

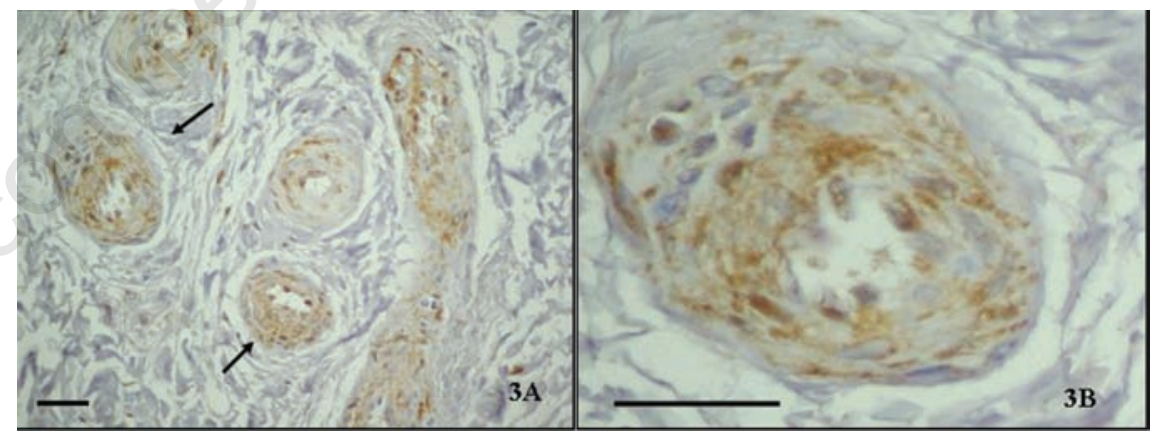

Figure 3. (A) Caspase 3 immunostaining in the posterior band of TMJ ID disc (x40); (B) Immunopositive vascular vessels are indicated with arrows (x100). Bar: $100 \mu \mathrm{m}$.

In conclusion, this study allows to hypothesize that angiogenesis is maintained localized thanks to the apoptotic process in degenerative disc tissues, thus vessel apoptosis activation in TMJ disc with ID could be regarded as a self-limiting process that tries to lead to vessel regression. In this way an inhibition of angiogenic vessels may prove to be a key strategy in limiting pathological angiogenesis, by cutting off the blood supply to tumors or by reducing harmful inflammation.

\section{References}

1. Beck H, Plate KH. Angiogenesis after cerebral ischemia. Acta Neuropathol 2009;117: 481-96.

2. Bogler 0, Mikkelsen T. Angiogenesis and apoptosis in glioma: two arenas for promising new therapies. J Cell Biochem 2005; 96:16-24.

3. Kirk S, Frank FA, Karlik S. Angiogenesis in 
multiple sclerosis: is it good, bad or an epiphenomenon? J Neurol Sci 2004;217: 125-30.

4. Rees L. The structure and function of the mandibular joint. Br Dental J 1954;96:125-33.

5. Dixon AD. Structure and functional significance of the intra-articular disc of the huma temporomandibular joint. Oral Surg Oral Med Oral Pathol 1962;15:48-59.

6. De Bont LG Liem RSB, Havinga P, Boering G. Fibrous component of the temporomandibular joint disk. Cranio 1985;3:369-73.

7. Bronstein SL, Merril RG. Clinical staging for TMJ internal derangement: application to arthropathy. J Craniomandib Disord 1992;6:7-16.

8. Yoshida H, Fujita S, Nishida M, lizuka T. Angiogenesis in the human temporomandibular joint studied by immunohistochemistry for CD34 antigen. J Oral Pathol Med 1999;28:289-92.

9. Leonardi R, Villari L, Bernasconi G, Piacentini C, Baciliero U, Travali S. Cellular S-100 protein immunostaining in human dysfunctional temporomandibular joint discs. Arch Oral Biol 2000;45:411-18.

10. Carlsson GE, Oberg T, Bergman F, Fajers CM. Morphological changes in the mandibular joint disk in temporomandibular joint pain dysfunction syndrome. Acta Odontol Scand 1967;25:163-81.

11. Scapino RP. Histopathology associated with malposition of the human temporomandibular joint disc. Oral Surg Oral Med Oral Pathol 1983;55:382-97.

12. Hall MB, Brown RW, Baughman RA. Histologic appearance of the bilaminar zone in internal derangement of the temporomandibular joint. Oral Surg Oral Med Oral Pathol 1984;58:375-81.

13. Castelli WA, Nasjleti CE, Diaz-Perez R, Caffesse RG. Histopathologic findings in temporomandibular joints of aged individuals. J Prosthet Dent 1985;53:415-19.

14. McCoy JM, Gotcher JE, Chase DC. Histologic grading of TMJ tissues in internal derangement. Cranio 1986;4:213-18.

15. Helmy ES, Timmis DP, Sharawy MH, Abdelatif 0, Bays RA. Fatty change in the human temporomandibular joint disc. Light and electron microscopy study. Int J Oral Maxillofac Surg 1990;19:38-43.

16. de Bont LGM, Stegenga B. Pathology of temporomandibular joint internal derangement and osteoarthrosis. Int $\mathrm{J}$ Oral Maxillofac Surg 1993;22:71-4.

17. Marchetti C, Piacentini C, Farina A, Bernasconi G, Calligaro A. A microscopic and immunocytochemical study of structural changes in dysfunctional human temporomandibular joint discs. Arch Oral Biol 1995;40:549-57.

18. Yoshida H, Fujita S, Nishida M, Iizuka T.
Angiogenesis in the human temporomandibular joint studied by immunohistochemistry for CD34 antigen. J Oral Pathol Med 1999;28:289-92.

19. Frank S, Hubner G, Breier G, Longaker MT, Greenhalgh DG, Werner S. Regulation of vascular endothelial growth factor expression in cultured keratinocytes. Implications for normal and impaired wound healing. J Biol Chem 1995;270:12607-13.

20. Ben-Av P, Crofford LJ, Wilder RL, Hla T. Induction of vascular endothelial growth factor expression in synovial fibroblasts by prostaglandin E and interleukin-1: a potential mechanism for inflammatory angiogenesis. FEBS Lett 1995;372:83-7.

21. Cohen T, Nahari D, Cerem LW, Neufeld G, Levi BZ. Interleukin 6 induces the expression of vascular endothelial growth factor. J Biol Chem 1996;271:736-41.

22. Kiga N, Tojyo I, Matsumoto T, Hiraishi Y, Shinora Y, Fujita S. Expression of lumican related to CD34 and VEGF in the articular disc of the human temporomandibular joint. Eur J Histochem 2010:54:152-7.

23. Carlevaro MF, Cermelli S, Cancedda R, Descalzi Cancedda F. Vascular endothelial growth factor (VEGF) in cartilage neovascularization and chondrocyte differentiation: auto-paracrine role during endochondral bone formation. J Cell Sci 2000;113: 59-9.

24. Huppertz B, Kaufmann H-G FP. The apoptosis cascade-morphological and immunohistochemical methods for its visualization. Anat Embryol (Berl)1999;200:1-18.

25. Mariani SM, Krammer PH. Differential regulation of TRAIL and CD95 ligand in transformed cells of the T and B lymphocyte lineage. Eur J Immunol 1998;28:973-82.

26. Ashkenazi A, Dixit AM. Death receptors: signaling and modulation. Science 1998; 281:1305-08.

27. Chapman HA, Riese RJ, Shi GP. Emerging roles for cysteine proteases in human biology. Annu Rev Physiol 1997;59:63-88.

28. Dimitroulis G. The role of surgery in the management of disorders of the temporomandibular joint: a critical review of the literature. Int $\mathrm{J}$ Oral Maxillofac Surg 2005;34:231-7.

29. Dolwick MF. Temporomandibular joint surgery for internal derangement. Dent Clin North Am 2007;51:195-208.

30. Miloro M, Henriksen B. Discectomy as the primary surgical option for internal derangement of the temporomandibular joint. J Oral Maxillofac Surg 2010;68:782-9.

31. Merrill RG, Yih WY, Langan MJ. An histological evaluation of the accuracy of TMJ diagnostic arthroscopy. Oral Surg 1990;70: 393-98.

32. Gynther GW, Holmlund AB, Reinholt FP.
Synovitis in internal derangement of the temporomandibular joint: correlation between arthroscopic and histologic findings. J Oral Maxillofac Surg 1994;52:913-17.

33. Leonardi R, Lo Muzio L, Bernasconi G, Caltabiano C, Piacentini C, Caltabiano M. Expression of vascular endothelial growth factor in human dysfunctional temporomandibular joint discs. Arch Oral Biol 2003;48:185-92.

34. Leonardi R, Loreto C, Barbato E, Polimeni A, Caltabiano R, Lo Muzio L. A histochemical survey of the human temporomandibular joint disc of patients with internal derangement without reduction. $\mathrm{J}$ Craniofac Surg 2007;18:1429-33.

35. Secchiero P, Gonelli A, Carnevale E, Corallini F, Rizzardi C, Zacchigna S, et al. Evidence for a proangiogenic activity of TNF-related apoptosis-inducing ligand. Neoplasia 2004;6:364-73.

36. Secchiero P, Gonelli A, Carnevale E, Milani D, Pandolfi A, Zella D, et al. TRAIL promotes the survival and proliferation of primary human vascular endothelial cells by activating the Akt and ERK pathways. Circulation 2003;107:2250-56.

37. Cantarella G, Risuglia N, Dell'eva R, Lempereur L, Albini A, Pennisi G, et al. TRAIL inhibits angiogenesis stimulated by VEGF expression in human glioblastoma cells. Br J Cancer 2006;94:1428-35.

38. Chen PL, Easton AS. Evidence that tumor necrosis factor-related apoptosis inducing ligand (TRAIL) inhibits angiogenesis by inducing vascular endhothelial cell apoptosis. Biochem Biophys Res Commun 2010;391:936-41.

39. Benndorf R, Boger RH, Ergun S, Steenpass A, Wieland T. Angiotensin II type 2 receptor inhibits vascular endothelial growth factor-induced migration and in vitro tube formation of human endothelial cells. Circ Res 2003;93:438-47.

40. Ashton AW, Ware JA. Thromboxane A2 receptor signaling inhibits vascular endothelial growth factor-induced endothelial cell differentiation and migration. Circ Res 2004;95:372-79.

41. Fruman DA, Meyers RE, Cantley LC. Phosphoinositide kinases. Annu Rev Biochem 1998;67:481-507.

42. Jones RG, Elford AR, Parsons MJ, Wu L, Krawczyk CM, Yeh WC, et al. CD28dependent activation of protein kinase B/Akt blocks Fas-mediated apoptosis by preventing deathinducing signaling complex assembly. J Exp Med 2002;196:335-48.

43. Loreto C, Musumeci G, Leonardi R. Chondrocyte-like apoptosis in temporomandibular joint disc internal derangement as a repair-limiting mechanism. An in vivo study. Histol Histopathol 2009; 
24:293-8.

44. Leonardi R, Almeida LE, Trevilatto PC, Loreto C. Occurrence and regional distribution of TRAIL and DR5 on temporomandibular joint discs: comparison of disc derangement with and without reduction. Oral Surg Oral Med Oral Pathol Oral Radiol Endod 2010;109:244-51.

45. Park JB, Kim KW, Han CW, Chang H.
Expression of Fas receptor on disc cells in herniated lumbar disc tissue. Spine 2001;26:142-46.

46. Wang D, Liu M, Song H, Wang M, Yang K, Zhang Y. Expression of Bax and caspase-3 and apoptosis in human lumbar intervertebral disc degeneration. Zhongguo Xiu Fu Chong Jian Wai Ke Za Zhi 2008;22:421-5.

47. Park JB, Lee JK, Park SJ, Kim KW, Riew
KD. Mitochondrial involvement in Fasmediated apoptosis of human lumbar disc cells. J Bone Joint Surg Am 2005;87:133842.

48. Hall MB, Brown RW, Baughman RA. Histologic appearance of the bilaminar zone in internal derangement of the temporomandibular joint. Oral Surg 1984;58: $375-81$. 